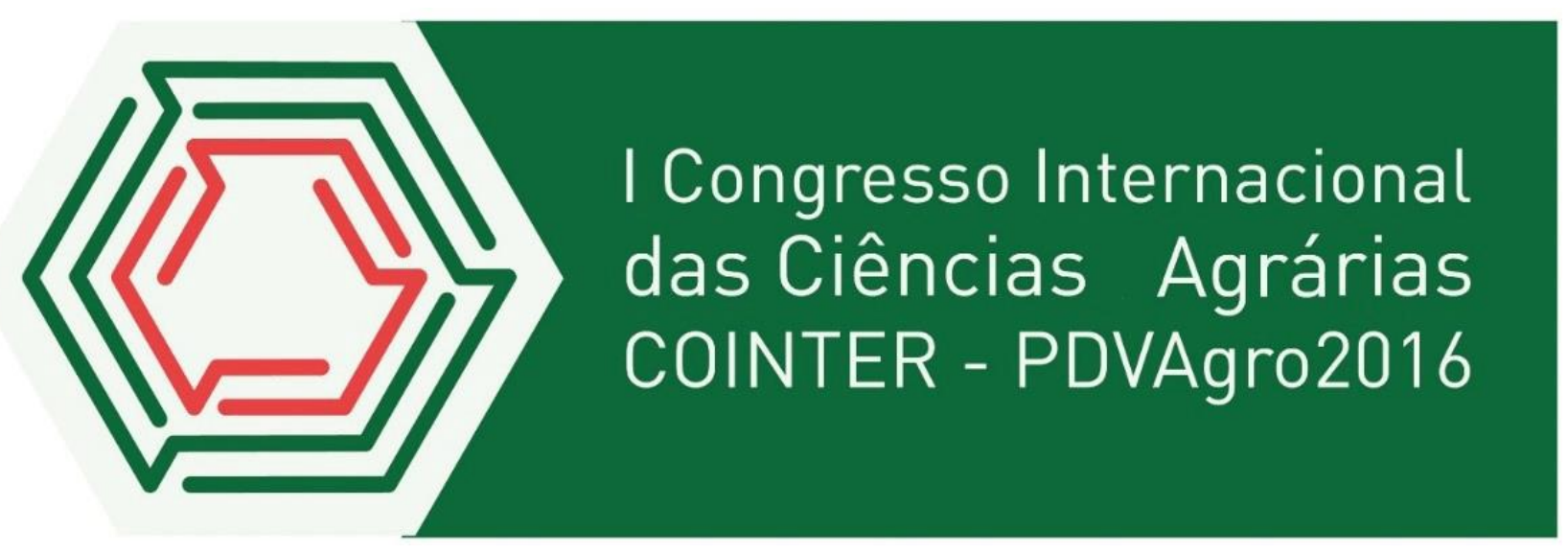

\title{
UNIDADE EXPERIMENTAL DE SISTEMA AGROFLORESTAL: O CASO DA PROPRIEDADE SÃO SEBASTIÃO/ LAGOA DE ITAENGA- PE
}

\author{
Apresentação: Relato de Experiência
}

Maria José da Silva ${ }^{1}$; Aline Carneiro de Paula ${ }^{2}$; Maria José Felipe Filha ${ }^{3}$; Guilherme José de Vasconcelos Soares ${ }^{4}$

\section{Introdução}

Os sistemas agroflorestais (SAF's) são consórcios de cultivos agrícolas com árvores que podem ser utilizados para reflorestamento e recuperação de áreas degradadas. Esse sistema ameniza limitações do terreno, minimiza riscos de degradação inerentes à atividade agrícola e aperfeiçoa a produtividade a ser obtida. Contribui também para reduzir a perda de fertilidade do solo e no ataque severo de insetos-pragas. As árvores são elementos fundamentais para a recuperação das funções ecológicas, uma vez que possibilita o restabelecimento de boa parte das relações entre as plantas e os animais. Os componentes arbóreos são inseridos como estratégia diminuir as perdas por erosão e aumentar a disponibilidade de matéria orgânica, restaurando a fertilidade do solo (EMBRAPA, 2004).

Um dos principais objetivos dos SAFs é a otimização no uso da terra, integrando a produção florestal com a produção de alimentos, possibilitando a conservação do solo e diminuir a pressão da utilização da terra pela produção agrícola (ENGEL, 1999).

Este trabalho tem como objetivo relatar sobre a implantação de uma unidade experimental

\footnotetext{
${ }^{1}$ Licenciatura em Ciências Agrárias, UFPB/CCHSA, mariasilvat.a@gmail.com

${ }^{2}$ Mestranda do Programa de Pós- graduação em Ciências Agrárias (Agroecologia), UFPB/CCHSA, alinecarneiro_paula@hotmail.com

${ }^{3}$ Bacharelado em Agroecologia, UFPB/CCHSA, mariareges33@hotmail.com

${ }^{4}$ Mestre em Administração e Comunicação Rural, UFRPE, gvsoares@bol.com.br
} 
de Sistema agroflorestal na propriedade São Sebastião, localizado no Sítio Marrecos no município de Lagoa de Itaenga-PE.

\section{Relato de Experiência}

Partindo do modelo de produção exploração convencional desenvolvida por Manoel Machado e seus familiares com práticas não sustentáveis como queima de restos culturais (coivara) e deposição de resíduos sólidos inorgânicos a céu aberto. Além dificuldade de água para produção no período de estiagem, e suas propriedades serem vizinhas a monocultura de cana - de - açúcar, pensando nesses desafios a ser superados é que a comunidade em parceria com Incubadora Tecnológica de Cooperativas Populares INCUBACOOP/UFRPE discutiu através de reuniões na associação a implantação da base experimental de SAF's em sua propriedade.

A propriedade familiar tinha uma área total de 2,5 há, a unidade experimental implantada utilizou uma área de 10m x 10m, essa se localizava próximo a nascente (cacimba) da propriedade.

O SAF foi composto pelo plantio de uma diversidade de culturas: espécies frutíferas (acerola, carambola, goiaba, graviola e caju); nativas (pitomba, pau brasil, ypê, jenipapo) leguminosas (feijão guandu, leucena) e forrageiras (palma).

Após acompanhamento período de 2 (dois anos) foi observado pelo grupo familiar várias questões que favoreceu melhor desenvolvimento em aspectos ambientas, tais como o nível de matéria orgânica do solo, a diversidade da flora e fauna, a produção de frutas. A partir dessa experiência o agricultor vivenciou os benefícios do SAF e decidiu adotar o sistema na totalidade da propriedade.

\section{Considerações}

Observa-se que a implantação de unidades experimentais de SAF's se mostra uma estratégia eficaz para adoção desses sistemas pelos agricultores.

\section{Referências}

Engel, V.L. Introdução aos Sistemas Agroflorestais. Botucatu: FEPAF, 1999.70 p. 
AGROPECUÁRIA, Empresa Brasileira de Pesquisa. Sistemas agroflorestais (SAF's). 2004. Disponível em: <https://www.embrapa.br/busca-de-produtos-processos-e- 